\title{
Medios de comunicación, viralización y restauración del patrimonio cultural: el efecto Ecce Homo
}

\author{
Antonio J. Sánchez Fernández \\ Doctor por la Universidad de Sevilla
}

RESUMEN:

En una sociedad tan inmediata y voluble resulta imprescindible determinar cómo nos relacionamos con el arte y el Patrimonio Cultural. En esta investigación se determinan los mecanismos y condicionantes que participan en el fenómeno del Ecce Homo de Borja. Se analiza la repercusión global en medios de comunicación e internet y su influencia en la transformación de su percepción y valorización, así como su impronta en los criterios de restauración. Se estudió y se sintetizó tanto el impacto más inmediato, reflejado en los comentarios del blog del Centro de Estudios Borjanos, como la evolución del argumentario en defensa de la conservación en su configuración actual. Igualmente, se realizó un examen explicativo del contexto sociocultural que envuelve a los hechos de Borja. Nace el efecto Ecce Homo como un proceso de patrimonialización posmoderno a partir de su interacción con las emociones (que aglutina cuestiones identitarias) y la viralización mediática.

\section{ABSTRACT:}

In such an immediate and conversational society, it is vital to determine how we relate to art and cultural heritage. This research determines the mechanisms and constraints that are involved in the phenomenon of Ecce Homo of Borja. It analyses the global media and online repercussion and its influence on the transformation of its perception and valuation, as well as its impact on restoration criteria. The most immediate impact is studied and summarised, reflected in comments on the blog of the Centro de Estudios Borjanos, as well as the evolution of the argument in favour of preserving its current presentation. Likewise, an explanatory examination is made of the sociocultural context which surrounds the events in Borja. And so the Ecce Homo effect appears as a process of postmodern heritage construction based on its interaction with emotions (which brings together identity issues) and media virality.

\section{PALABRAS CLAVE:}

Medios de comunicación; Viral; Conservación-Restauración; Criterios de intervención; Ecce Homo; Patrimonio Cultural.

\section{KEYWORDS:}

Media; Viral; Conservation-Restoration; Intervention criteria; Ecce Homo; Cultural heritage. 


\section{Introducción}

En 2012 se produjo un hecho de gran impacto global: una persona de avanzada edad intervino, sin formación específica ni criterio profesional, una pintura mural ubicada en el Santuario de la Misericordia (Borja, Zaragoza). El óleo sobre muro era obra de Elías García Martínez (s. XX), copia del Ecce Homo de Guido Reni. El acontecimiento quedó impregnado por la inocencia de la octogenaria que narraba cómo había retocado la obra otras veces, y que, en este caso, se encontraba en una fase intermedia de la intervención. No lo había dado por concluido.

Con el salto a los medios de comunicación internacionales, se produjo un proceso de viralización con un impacto global. Asimismo, ha tenido otras consecuencias, como un desarrollo turístico y económico de la zona.

El objetivo del presente texto es analizar la repercusión de la pseudorestauración del Ecce Homo de Borja (en adelante, EHB) en los medios de comunicación, los mecanismos de patrimonialización de dicha obra y cómo pueden influir en los criterios de intervención en bienes culturales. Entendemos que nos encontramos ante un caso paradigmático en el que se producen nuevas relaciones entre las personas y los objetos, valorándolo como un elemento identitario a conservar.

La aproximación científica a este fenómeno sólo se ha producido por Bergua, Serrano, Valero y Plumed ${ }^{1}$, desde el punto de vista sociológico y por $\mathrm{M}^{\mathrm{a}}$ Encarnación Ripollés Adelantado y $\mathrm{M}^{\mathrm{a}}$ Mercedes Núñez Motilva ${ }^{2}$, desde los aspectos técnicos como conservadoras-restauradoras. Los primeros, aportan novedosos argumentos para estudiar este fenómeno, aunque cercado a su disciplina. Las segundas, contribuyen con el informe técnico de conservación-restauración al conocimiento de la obra original y el repinte. También se plasma el conflicto que presenta

BERGUA, José Ángel; SERRANO, C.; VALERO, Diana y PLUMED, Marta, "Sociedad red, arte dialogado y demopoiesis: El Ecce Homo de Borja”, en International Review of Sociology: Revue Internationale de Sociologie, Volumen 23, № 2, Oxford, 2013, pp. 482-498, doi: https://doi.org/10.1080/03906701.2013.804747

RIPOLLÉS ADELANTADO, M ${ }^{\text {a }}$ Encarnación y NÚÑEZ MOTILVA, Ma Mercedes, Informe sobre el Ecce Homo de la iglesia del santuario de la Misericordia de Borja (Zaragoza), Zaragoza, 2012, http://www.borja.es/ noticias/3-cultura/276-informe-y-analisis-realizados-al-ecce-homo, (consultado 02/05/2017). los criterios de restauración, aceptados por la comunidad científica, frente a la influencia y repercusión social de algunos objetos.

Destacamos también la Tesis de Máster: "Behind the Ecce Homo: Rural Development Policy and the Effects of Depopulation on the Preservation of Spanish Heritage" 3 . No obstante, el objetivo fundamental de esta Tesis diverge de nuestros objetivos. Sánchez Sánchez pone en relación los efectos de la despoblación y el patrimonio, usando los hechos de Borja como pretexto para comprender las estrategias de conservación del patrimonio en un entorno rural.

Por otro lado, resultan muy significativas las aportaciones de Llorenç Prats ${ }^{4}$ y Ariño Villarro$\mathrm{ya}^{5}$ al concepto de patrimonio cultural y sobre todo a los procesos de patrimonialización cultural. Asimismo, destacan los textos de Cecilia Bákula $^{6}$ y Agudo Torrico ${ }^{7}$ en torno al concepto de identidad cultural y los riesgos que comporta.

\section{Material y métodos}

En primer lugar, se realizó un análisis descriptivo derivado de los medios de comunicación e internet, $y$, posteriormente, se articuló un análisis explicativo. Para el primero, se estudió la repercusión en internet y en la prensa (digital y escrita). Así, en la figura 1, se muestra la clasificación y la proporcionalidad de los comentarios en el blog del Centro de Estudios Borjanos en el que se denunciaron los hechos inicialmente. Quedan limitados al mes en el que se produjeron (agosto de 2012). Del mismo modo, en la figura 2, se expone la clasi-

\footnotetext{
SANCHEZ-SANCHEZ, Alberto, Behind the Ecce Homo: Rural Development Policy and the Effects of Depopulation on the Preservation of Spanish Heritage, Unpublished Master's Thesis, Columbia University, Graduate School of Architecture, Planning, and Preservation, Nueva York, 2016.

4 PRATS, Llorenç, Antropología y Patrimonio, Ariel, Barcelona, 1997.

5 ARIÑO VILLARROYA, Antonio, "La patrimonialización de la cultura y sus paradojas”, en Tecnología, cultura experta e identidad en la sociedad del conocimiento, Universidad del País Vasco, Servicio de Publicaciones, Bilbao, 2009, pp. 131-156.

6 Cecilia Bákula, "Reflexiones en torno al patrimonio cultural”, en Revista Turismo y Patrimonio, № 1, Lima, 2000, pp. 167-174.

7 AGUDO TORRICO, Juan, "Patrimonio etnológico. Recreación de identidades y cuestiones de mercado", en Patrimonio Inmaterial y gestión de la diversidad, Consejería de Cultura, Sevilla, 2005, pp.196-213.
} 


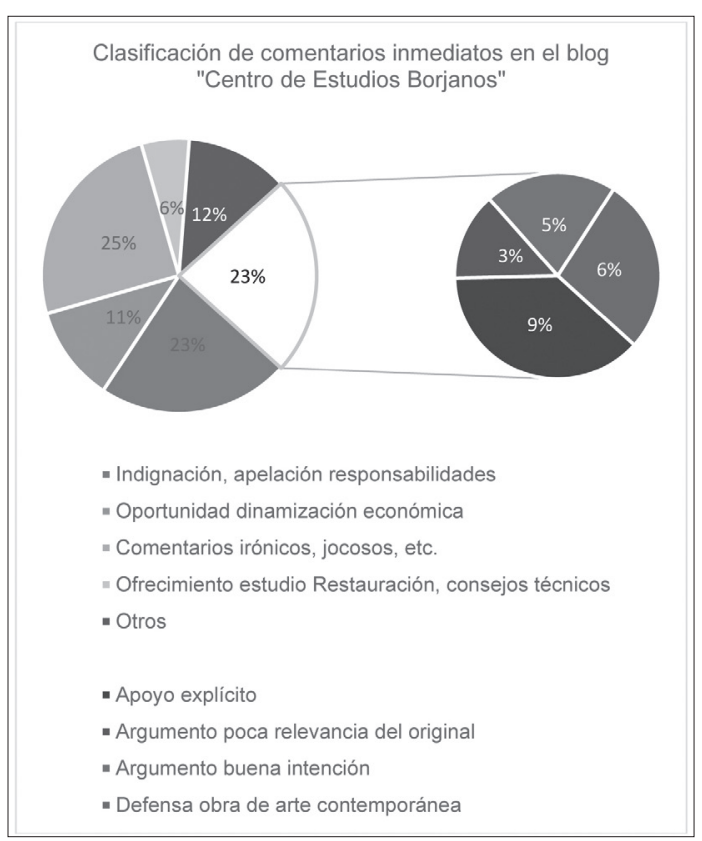

Fig. 1. Análisis de 124 comentarios en el blog del Centro de Estudios Borjanos del 7 al 25 de agosto del 2012.

ficación y proporcionalidad de los comentarios en la plataforma change.org de la petición de conservación del EHB. Fueron registrados en 2013 y se ha realizado un muestreo de 1000 comentarios. Se sintetizaron las líneas generales de argumentación y las diez principales nacionalidades de los comentaristas (ver Fig. 3). En segundo lugar, se realizó un registro y categorización de los titulares de prensa más significativos, que hacen alusión de alguna forma al EHB, entre 2012 y 2016 y distintos alcances: local, regional y nacional (tabla 1).

Por otro lado, para el análisis explicativo realizamos una contextualización sociocultural, puesto que nos parecía fundamental para entender cómo encajan los hechos de Borja en la conciencia contemporánea. Asimismo, se elaboró una contextualización de los fenómenos de patrimonialización y viralización de los contenidos compartidos.

\section{Análisis y resultados}

\subsection{Análisis del impacto en medios de comunicación}

El día 7 de agosto de 2012 el Centro de Estudios Borjanos publicó en su blog una entrada titulada: "un hecho incalificable", que describía lo ocurrido con la pintura mural. La noticia saltaba a un periódico regional llamado Heraldo de Aragón y al día siguiente aparecía en uno de los diarios principales del Reino Unido: The Guardian $^{8}$. Posteriormente, se publicaban sendas noticias en The Washington Post ${ }^{9}$ y en New York Times ${ }^{10}$. Se había abierto un proceso de viralización donde la imagen y la noticia se divulgaban rápidamente en medios de comunicación y redes sociales. También ha tenido otras repercusiones como aplicaciones móviles, aumento de turismo local, imagen de marca y otros eventos como un concurso internacional de pintura.

El impacto en cifras es revelador. En dicho blog, a fecha de 10 de septiembre de 2014 había más de 240.000 visitas ${ }^{11}$. Recientemente, a fecha de febrero de 2018 se recogen 2.500.000 visitas. Por otro lado, no sólo es indicativo la rapidez de la difusión de la noticia, es decir el proceso de viralización, sino la evolución y el concepto que representa.

De esta manera, se registra los comentarios del propio blog del Centro de Estudios Borja$\operatorname{nos}^{12}$ (ver Fig. 1). Se produjeron un total de 124 comentarios desde el 7 al 25 de agosto de 2012. Este análisis refleja la primera impronta y las reacciones más inmediatas y cercanas al repinte del EHB. Así, se desprende una polarización de las opiniones en dos líneas:

8 JONES, Sam, "Spanish church mural ruined by well-intentioned restorer", The Guardian, Londres, 22 de agosto de 2012, https://www.theguardian.com/artanddesign/2012/aug/22/spain-church-mural-ruin-restoration, (consultado 02/05/2017).

9 KHAZAN, Olga, "Spanish woman botches 'Ecce Homo' painting in an attempt to restore it". Washington Post. Washington, 23 de agosto de 2012, https://www. washingtonpost.com/blogs/blogpost/post/spanishwoman-botches-ecce-homo-painting-in-an-attemptto-restore-it/2012/08/23/263bd0e2-ed42-11e1-b09d07d971dee30a_blog.html?utm_term=.9353aa5f79c7, (consultado 02/05/2017).

10 MINDER, Raphael (2012, August 23). "Despite good intentions, a Fresco in Spain is ruined”, The New York Times, New York, 23 de agosto de 2012, http://www. nytimes.com/2012/08/24/world/europe/botched-restoration-of-ecce-homo-fresco-shocks-spain.html?_r_0, (consultado 02/05/2017).

11 BERGUA, José Ángel; SERRANO, C.; VALERO, Diana y PLUMED, Marta, "Sociedad red..., opus cit., p. 485.

12 CENTRO DE ESTUDIOS BORJANOS, "Un hecho incalificable", en Centro de Estudios Borjanos. Institución Fernando el Católico [Web log post], Borja (Zaragoza), 7 de agosto de 2012, http://cesbor.blogspot.com. es/2012/08/un-hecho-incalificable.html (consultado 01/05/2017). 
- Línea de opinión negativa (un total del 48\%):

- Un 23\% de sentimientos de indignación y búsqueda de represalias o responsabilidades.

- Un 25\% de comentarios críticos, jocosos e irónicos, haciendo referencia a un gag cómico.

- Línea de opinión positiva (un total del $34 \%)$ :

- Un 11\% que lo visualiza como una oportunidad de dinamización económica de la comarca.

- Un 23\% que se manifiesta a favor del repinte, argumentando:

a) La poca relevancia del original

b) Empatía con la buena intención de la autora del repinte

c) Elevación del repinte a obra autónoma de arte contemporáneo

d) Simple apoyo explícito

Del mismo modo, en 2013, se realizó una petición de "mantenimiento de la nueva versión del Ecce Homo de Borja"13 a través de la plataforma change.org (ver Fig. 2). La petición consiguió 23.225 firmas de más de 60 nacionalidades distintas (ver Fig. 3).

Se han analizado 1000 comentarios justificando la necesidad de conservarlo, que los sintetizamos en las siguientes líneas argumentales generales:

a) Empatía/ simpatía por la autora del repinte.

b) Aceptación como obra de arte autónoma.

c) Icono cultural contemporáneo.

d) Quod feci, feci.

e) Identificación con sentimientos positivos.

f) Reflejo de valores religiosos.

g) Superación al original: carácter único y de mayor valor e interés.

h) Promoción turística y recurso económico.

i) Rechazo a poderes establecidos/ desacralización del arte: En esta línea argumental se identifican poderes establecidos, tanto la institucionalización del arte (conocimiento experto) como la Iglesia.

DOMINGO, Javier, "Mantenimiento de la nueva versión del Ecce Homo de Borja”, en Change.org, 2013, https://www.change.org/p/ayuntamiento-de-borja-zaragoza-mantenimiento-de-la-nueva-versi\%C3\%B3n-del-ecce-homo-de-borja (consultado 01/05/2017) j) "Porque sí".

k) Otros.

Por otro lado, en la figura 4 podemos ver una serie de titulares de prensa de distintos medios de comunicación entre 2012 y 2016, que hacen referencia, de alguna u otra manera, al EHB. De la lectura de los mismos podemos hacer una clasificación de las líneas conceptuales que implican los efectos de este hecho:

1. Repercusión económica y socio-cultural: algunos de los titulares indican el aprovechamiento mercantil y de la imagen. También de la improvisada campaña de publicidad del pueblo o de la creación de distintos formatos audiovisuales inspirados en este hecho.

2. Ejemplo paradigmático comparativo: se establece como referente de mala praxis de restauración.

3. Entidad propia como obra de arte contemporáneo: la adquisición de iconicidad, hace sensible su interpretación en otras obras de arte, llegándose a aceptar el propio repinte del EHB como obra artística autónoma. De esta forma, la imagen ocupa el puesto 52/100 de un ranking internacional de capacidad icónica de obras de arte, según la revista $\operatorname{ArtInfo}^{14}$.

\subsection{Un contexto posmoderno para consumir el Ecce Homo de Borja}

La expresión posmoderno se puso en boga en la década de 1980 a través del filósofo Jean François Lyotard. Moret identifica el inicio de la postmodernidad en el momento en el que el progreso (avances tecnológicos, intelectuales, económicos, políticos y sociales) deja de ser eficaz y ya no beneficia a la humanidad ${ }^{15}$.

Con el avance científico se produce un desafecto por los "metarrelatos". Para la concepción de Lyotard, "los metarrelatos son asumidos

4 FORBES, Alexander, “Spanish Octogenarian's Disastrous Unauthorized Art Restoration Yields Surprisingly Avant-Garde Results”, en Blouin Artinfo. Nueva York, 23 de Agosto de 2012, http://www.blouinartinfo.com/news/ story/821028/spanish-octogenarians-disastrous-unauthorized-art-restoration, (consultado 01/05/2017).

15 MORET, Román, "La Posmodernidad: intento de aproximación desde la Historia del pensamiento", en Bajo Palabra. Revista de Filosofía. II Época, № 7, Madrid, 2012, p. 341. 

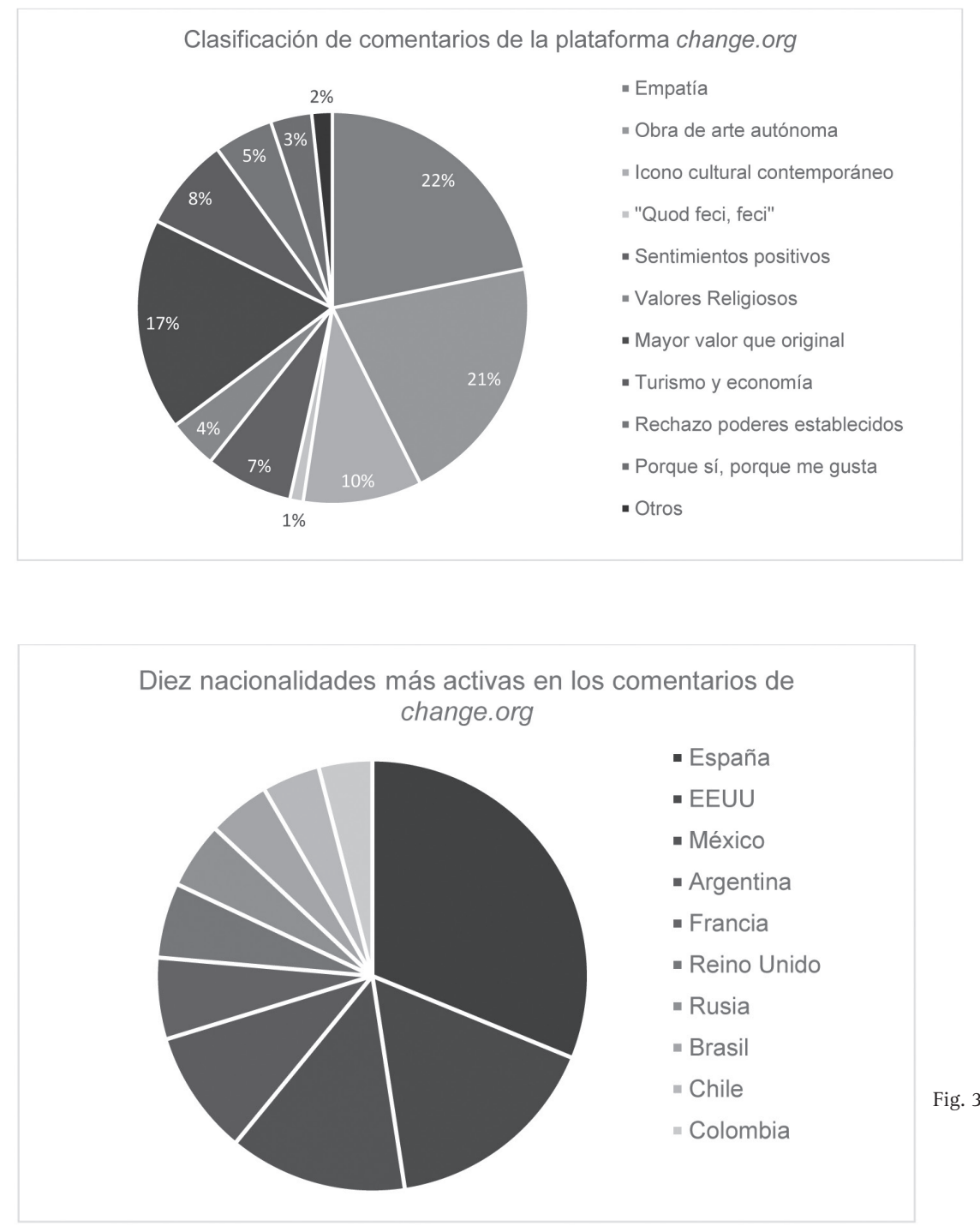

Fig. 2. Proporción de los comentarios analizados en la plataforma change.org en apoyo a la conservación del EHB.

como discursos totalizantes y multiabarcadores, en los que se asume la comprensión de hechos de carácter científico, histórico y social de forma absolutista, pretendiendo dar respuesta y solución a toda contingencia" ${ }^{16}$. Así, la posmodernidad se opone a las grandes generalizaciones, a las teorías totalizadoras, de manera que se acepta la relatividad de la verdad que aparece como indefinida, interpretativa y local ${ }^{17}$.

Asimismo, en la posmodernidad se materializa simultáneamente una contradicción entre la universalización y la individualización. La

16 LYOTARD, Jean-François, La condición postmoderna. Informe sobre el saber, Ediciones Cátedra, 2a edición, Madrid, 1991, p.4.

17 HARRIS, Marvin, Teorías sobre la cultura en la era posmoderna, Ed. Crítica, 2a edición. Barcelona, 2007, p.90. universalización se vincula a un sentimiento de autonomía/liberación de la sociedad, aunque contribuye a homogeneizarla, $\mathrm{y}$, al mismo tiempo, esta sociedad reivindica una individualización con el objetivo de no parecerse a los demás ${ }^{18}$. Igualmente, la razón queda subordinada por las emociones. Según Marvin Harris, "se da preminencia al corazón sobre la cabeza, a lo espiritual sobre lo mecánico, a lo personal sobre lo impersonal" ${ }^{19}$.

También existe una confrontación entre la noción de historia. Mientras que la concepción moderna se establece como recuperación o renacimiento, la posmoderna se concibe como una experiencia de lo nuevo que, además, se

18 MORET, Román, "La Posmodernidad..., opus cit., p. 343. 19 HARRIS, Marvin, Teorías sobre..., opus cit., p.90. 


\begin{tabular}{|c|c|c|}
\hline Fecha & Titular & Fuente \\
\hline 19/07/2016 & Una figura del siglo XVII, candidata a suceder al Ecce Homo de Borja & EL MUNDO \\
\hline 16.07.2016 & $\begin{array}{l}\text { Alemania ya tiene su 'Ecce Homo': una anciana destroza una obra al } \\
\text { rellenarla como si fuera un crucigrama }\end{array}$ & VOZPÓPULI \\
\hline 07/07/2016 & La autora del ecce homo ya tiene su propio museo en Borja & $A B C$ \\
\hline 05/07/2016 & El Ecce Homo: de Borja a la Universidad de Columbia & $\begin{array}{l}\text { Heraldo de } \\
\text { Aragón }\end{array}$ \\
\hline 17/06/2016 & $\begin{array}{l}\text { El Eccehomo de Borja, en un documental británico que se estrenará en } \\
\text { julio }\end{array}$ & $\begin{array}{l}\text { Heraldo de } \\
\text { Aragón }\end{array}$ \\
\hline 21/04/2016 & Cola para dormir junto al Ecce Homo de Borja & El Correo \\
\hline $11 / 03 / 2016$ & El Castillo de Matrera en Cádiz: ¿otro Ecce Homo? & elPeriódico \\
\hline 07/03/2016 & El Eccehomo de Borja ya tiene listo su Centro de Interpretación & $A B C$ \\
\hline 01/12/2015 & $\begin{array}{l}\text { El Ecce Homo de Borja dará lugar a un documental, una ópera, un } \\
\text { cuento y mucho 'merchandising' }\end{array}$ & 20 minutos \\
\hline 19/10/2015 & La destrucción del Arco de la Isla está al nivel del Ecce Homo de Borja & Diariodeburgos.es \\
\hline 05/05/2015 & Destrozan diez mosaicos antiguos 'a lo Ecce homo' en Turquía & Libertad Digital \\
\hline 23/12/2014 & $\begin{array}{l}\text { Bodegas Aragonesas lanza su vino con la imagen del Ecce Homo de } \\
\text { Borja }\end{array}$ & elEconomista.es \\
\hline 18/12/2014 & Borja, el pueblo que "revivió" gracias al Ecce Homo & perfil.es \\
\hline 15/12/2014 & $\begin{array}{l}\text { Cómo el Cristo de Borja salvó la economía de un pueblo, según 'The } \\
\text { New York Times' }\end{array}$ & EL PAIS \\
\hline $27 / 08 / 2014$ & $\begin{array}{l}\text { Si pensabas que el Ecce Homo era el cuadro más estrambótico de } \\
\text { Borja, espera a conocer al Ecce Borbón }\end{array}$ & PÚBLICO \\
\hline $21 / 08 / 2014$ & $\begin{array}{l}\text { El eccehomo sigue recibiendo más de } 2.000 \text { visitas al mes después de } \\
\text { dos años }\end{array}$ & $\begin{array}{l}\text { Heraldo de } \\
\text { Aragón }\end{array}$ \\
\hline 20/08/2014 & ¿Un nuevo eccehomo en Lugo? & 20 minutos \\
\hline 08/08/2014 & $\begin{array}{l}\text { El Ecce Homo de Borja ha recibido } 140.000 \text { visitantes desde que } \\
\text { Cecilia lo «restauró» }\end{array}$ & LA RAZÓN \\
\hline $06 / 05 / 2014$ & $\begin{array}{l}\text { El "Ecce homo" de Borja, un negocio redondo: } 70.000 \text { euros y mil } \\
\text { visitas mensuales }\end{array}$ & EUROPAPRESS \\
\hline 05/05/2014 & $\begin{array}{l}\text { La chapuza más rentable: } 70.000 \text { euros en entradas para ver el } \\
\text { Eccehomo de Borja }\end{array}$ & $\mathrm{ABC}$ \\
\hline 13/04/2014 & Cecilia y el 'eccehomo' de Borja se pasan a la música & $\begin{array}{l}\text { Heraldo de } \\
\text { Aragón }\end{array}$ \\
\hline 29/11/2013 & Colalucci: "La restauración del eccehomo de Borja es un error grave" & $\begin{array}{l}\text { Heraldo de } \\
\text { Aragón }\end{array}$ \\
\hline 07/09/2012 & $\begin{array}{l}\text { El eccehomo de Borja convertido en Warhol, Klimt o Leonardo en una } \\
\text { exposición }\end{array}$ & 20 minutos \\
\hline 24/08/2012 & El eccehomo de Borja contará con vigilancia privada & EL PAIS \\
\hline 23/08/2012 & $\begin{array}{l}\text { La «restauradora» del Ecce Homo de Borja podría acabar ante la } \\
\text { Justicia }\end{array}$ & $A B C$ \\
\hline
\end{tabular}

Fig. 4. Relación de titulares de prensa que hacen referencia al EHB, entre 2012 y 2016.

identifica con lo valioso. Así, el progreso artístico se asienta sobre esta base: la repercusión del instante de novedad, desembocando en una continua inauguración. De esta forma, "el ideal del progreso es algo vacío y su valor final es el de realizar condiciones en que siempre sea posible un nuevo progreso" 20 .

Por otro lado, en la sociedad actual todo puede ser un objeto consumible. Esto responde a la estrategia de consumo de masas o el círculo sinfín de producción y consumo, donde lo indispensable y necesario cede su lugar a lo superfluo e innecesario ${ }^{21}$, creando una dinámica de condiciones nunca satisfechas ${ }^{22}$. Al mismo tiempo, los usos de consumo tienen una doble polaridad que permite expresar tanto la filia-

20 VATTIMO, Gianni, El fin de la modernidad. Nihilismo $y$ hermenéutica en la cultura posmoderna, Ed. Gedisa, 2a edición, Barcelona, 1987, p. 15.

21 MORET, Román, "La Posmodernidad..., opus cit., p. 344.

22 LÓPEZ DE AYALA, Ma Cruz, "El análisis sociológico del consumo: una revisión histórica de sus desarrollos teóricos", en Sociológica. Revista de pensamiento social, No 5, A Coruña, 2004, pp. 167-168, http://ruc.udc.es/ dspace/handle/2183/2725, (consultado 08/05/2017). ción a un determinado grupo social, como los propios gustos personales ${ }^{23}$. Es decir, estos fenómenos se conciben como una práctica social donde las personas se expresan, realizan y se comunican con otros, creando su propia identidad, reafirmándose a sí mismos, en procesos de afiliación a grupos y alejamiento de otros ${ }^{24}$. Detrás de estos patrones existe una búsqueda del placer y la realización de experiencias a través del propio consumo ${ }^{25}$.

\subsection{Procesos de patrimonialización y la carga inalámbrica de significación del Ecce Homo de Borja}

Para Llorenç Prats, el proceso de patrimonialización se elabora en dos fases complementarias entre sí: por un lado, se debe a una "in-

${ }^{23}$ LÓPEZ DE AYALA, Ma Cruz, "El análisis sociológico...”, opus cit., p. 164.

24 LÓPEZ DE AYALA, Ma Cruz, "El análisis sociológico...”, opus cit., p. 180.

25 LÓPEZ DE AYALA, Ma Cruz, "El análisis sociológico...", opus cit., p. 176. 
vención" interesada de algún colectivo o individuo, y por otro, a una construcción social de la realidad: el sujeto colectivo (la sociedad) no activa los procesos de patrimonialización, sino que existen agentes (en primer lugar, los poderes constituidos) con la capacidad de proponer y conquistar adhesiones ${ }^{26}$. La construcción social de determinados objetos como patrimonio cultural es un concepto moderno y se origina como expresiones testimoniales, con un valor creativo y/o documental, y como legado del pasado susceptible de ser conservado: es considerado como un bien comunitario ${ }^{27}$.

Sin embargo, el factor que delimita el concepto actual de patrimonio es la facultad de poder simbolizar una identidad ${ }^{28}$. El símbolo elabora intensas emociones a partir de conceptos y creencias ${ }^{29}$. Así, sentimientos y emociones no sólo son procesos fisiológicos: son relaciones. De esta manera, la dinámica de la experiencia puede modificar la expresión de los sentimientos y las emociones ${ }^{30}$, y éstos son el reflejo individual de la compilación cultural del grupo ${ }^{31}$. Es decir, con las emociones se establecen una afiliación con la comunidad social.

También, para Vigotsky, "todo lo que nos causa un efecto emocional coincidente tiende a unirse entre sí pese a que no se vea entre ello semejanza alguna ni exterior ni interior" ${ }^{32}$. Por lo tanto, la consecuencia más importante radica en que se establece una sensación de pertenencia a una comunidad al desarrollar lazos afectivos con el conjunto de miembros ${ }^{33}$. La evocación emocional de los objetos va a depender "del contexto histórico-cultural, de la educación, de la propia sensibilidad del individuo, de

26 PRATS, Llorenç, Antropología..., opus cit., pp. 20-21, 29.

27 ARIÑO VILLARROYA, Antonio, "La patrimonialización de...", opus cit., pp. 132-133.

28 PRATS, Llorenç, Antropologia..., opus cit., p. 22 y ARIÑO VILLARROYA, Antonio, "La patrimonialización de...”, opus cit., pp. 134-135.

29 PRATS, Llorenç, Antropología..., opus cit., p. 29.

30 LE BRETON, David, Las pasiones ordinarias. Antropología de las emociones, Ediciones Nueva Visión, Buenos Aires, 1999, p. 123.

31 LE BRETON, David, Las pasiones ordinarias...", opus cit., p. 117.

32 VIGOTSKY, Lev Semonovich, La imaginación y el arte en la infancia, Akal, Madrid, 1998, p. 22.

33 GÓMEZ REDONDO, Carmen, "El origen de los procesos de patrimonialización: la efectividad como punto de partida”, en EARI Educación Artística Revista de Investigación, № 5, Universitat de València: Institut de Creativitat i Innovacions Educatives, Valencia, 2014, p. 74. las circunstancias de recepción de ese bien, así como del conocimiento de los valores de uso, material y simbólico" ${ }^{34}$.

En definitiva, nos encontramos ante un concepto de identidad cultural, que para Molano "encierra un sentido de pertenencia a un grupo social con el cual se comparten rasgos culturales, como costumbres, valores y creencias"35. Y, además, "surge por diferenciación y como reafirmación frente al otro" ${ }^{36}$.

Para Bákula, el patrimonio cultural puede expresar esta identidad. No obstante, reconoce el carácter cambiante condicionado por factores externos y la continua retroalimentación entre uno y otro ${ }^{37}$.

Así, un elemento susceptible de ser patrimonio puede adquirir distintos significados si lo entendemos no sólo como un objeto sino como una dinámica de relación con el individuo. Una cultura contemporánea que se centra en los procesos y las relaciones puede configurar mucho más rápido la patrimonialización de una obra. Para Gómez Redondo, "entendemos el proceso de patrimonialización como el proceso por el cual se genera un vínculo patrimonial, en cuanto a que el individuo compone unos valores propios para el objeto al que se enfrenta, un aprendizaje significativo asociado a dicho patrimonio. Al otorgar valores, el individuo da identidad a la obra y se identifica frente a ella, o con ella frente a la sociedad en un proceso en el que la obra forma ya, parte del yo" ${ }^{38}$.

En el caso del EHB las relaciones entre elementos ha creado un vínculo emocional con una apropiación de los procesos patrimonializadores. En un contexto de modernidad avanzada, el patrimonio puede maniobrar como retórica publicitaria y forjar la reivindicación de propiedad por parte de individuos o comunidades $^{39}$. En la actualidad, existen también dos

34 GÓMEZ REDONDO, Carmen, "El origen de los procesos...", opus cit., p. 71.

35 MOLANO L., Olga Lucía, "Identidad cultural un concepto que evoluciona”, en Ópera, № 7, Bogotá, 2007, p. 73.

36 Idem

37 Cecilia Bákula, "Reflexiones en torno...”, opus cit., p. 169.

38 GÓMEZ REDONDO, Carmen, "Procesos de patrimonialización en el arte contemporáneo”, en EARI Educación Artística Revista de Investigación, № 2, Universitat de València: Institut de Creativitat i Innovacions Educatives, Valencia, 2011, pp. 110-111.

39 ARIÑO VILLARROYA, Antonio, "La patrimonialización de...", opus cit., pp. 131. 
dinámicas de patrimonialización emergentes: comunidades locales y movimientos sociales y el turismo y la globalización del consumo del patrimonio cultural ${ }^{40}$. Y la construcción del EHB como elemento a salvaguardar participa de ambas.

\subsection{La viralización como vehículo de patrimonialización del Ecce Homo de Borja}

La acción de compartir contenidos en línea resulta un fenómeno de cotidianidad y también tiene un impacto en el individuo como consumidor. Así, uno de los aspectos más interesantes de la viralización de contenidos es la proyección positiva con la que se puede percibir al individuo que lo comparte. Cada persona se presenta como portador-contenedor de información que puede ser valorada por su círculo de contactos $^{41}$. Del mismo modo, la acción de compartir está ligada al concepto de "novedad", puesto que nos sitúa en posición de vanguardia: "compartimos cosas que descubrimos antes que nuestros contactos"42. Igualmente, compartimos un contenido que se relaciona con todo aquello que consideramos que forma parte de nuestra identidad. De esta manera, también nos definimos respecto a nuestro colectivo $^{43}$. En este sentido, cada acto de compartir el EHB confirma nuestra vinculación al grupo al que pertenecemos.

No obstante, ciertos elementos compartidos son más virales que otros. Algunos autores han profundizado en los principales aspectos que ayudan a la viralización de contenidos. Así, existen factores que pueden favorecer la transmisión social, como las emociones ${ }^{44}$. En primer lugar, se comparte mucho más las noticias po-

40 ARIÑO VILLARROYA, Antonio, "La patrimonialización de...", opus cit., p. 136.

41 DAFONTE GÓMEZ, Alberto, "Aproximación teórica al concepto de viralidad desde el punto de vista de la comunicación. Aplicación y repercusiones en los contenidos publicitarios audiovisuales", en El nuevo diálogo social: organizaciones, públicos y ciudadanos, Campgráfic, Valencia, 2015, p. 606.

42 Idem.

43 DAFONTE GÓMEZ, Alberto, "Aproximación teórica...", opus cit., p. 607.

44 BERGER, Jonah \& MILKMAN, Katherine L, "What Makes Online Content Viral?", en Journal of Marketing Research, Volúmen 49, № 2, Chicago, 2012, pp. 192-205. sitivas que las negativas ${ }^{45}$, predominando las emociones de sorpresa y alegría ${ }^{46}$. Así, en la figura 1 podemos ver que el $25 \%$ de los comentarios tienen un componente jocoso. Entre otros aspectos, esta visión amable y divertida de los acontecimientos de Borja contribuyó a su rápida difusión.

Sin embargo, existe una relación directa entre la evocación de emociones de mayor excitación (positivas o negativas) con la viralidad de la noticia ${ }^{47}$. En definitiva, todas aquellas emociones que inciten a la actividad (indignación, optimismo, incluso la admiración, etc.) influyen en una mayor susceptibilidad a ser compartido, frente a emociones asociadas al recogimiento, como la tristeza.

Así, existe un factor de sentimientos proactivos en el EHB: en un primer momento, se reflejaron respuestas de indignación (ver Fig. 1), que, como hemos visto, repercute directamente en la decisión de compartir este contenido por los medios de comunicación e internet. Del mismo modo, a medida que se modula la percepción de estos hechos, se registra una defensa como obra de arte autónoma que se articula a modo de icono contracultural (subversión) (ver figs. 1 y 2). También, la protagonista, que tiene un componente de ingenuidad y no había una mala intención en la actuación, provoca una empatía (ver Fig. 2) que incluso hace que las posibles repercusiones legales sean vistas como algo abusivo.

El aporte destacado del caso del EHB se encuentra en su capacidad de simbolizar una identidad cultural a partir de emociones compartidas. En este sentido, podemos apreciar similitudes con la noticia viral de la retirada de la obra "Presos Políticos" de Santiago Sierra en ARCO (2018) ${ }^{48}$. En esta cuestión, se producen reacciones derivadas de una serie de sentimien-

45 BERGER, Jonah \& MILKMAN, Katherine L, "What Makes...", opus cit., p. 201.

46 DAFONTE GÓMEZ, Alberto, "Claves de la publicidad viral. De la motivación a la emoción en los vídeos más compartidos", en Comunicar: Revista cientifica iberoamericana de comunicación y educación, No 43, 2014, p. 206.

47 BERGER, Jonah y MILKMAN, Katherine L, "What Makes...", opus cit., p. 201.

48 LÁZARO Margarita y PRATS Marina, "Ifema manda retirar de ARCO la obra de Santiago Sierra 'Presos Políticos'”, en Haffpost, 21 de febrero de 2018, recuperado de http://www.huffingtonpost.es/2018/02/21/ retiran-de-arco-la-obra-de-santiago-sierra-presos-politicos_a_23367154/ 
tos y se sintetiza como símbolo de identidades (defensa de la libertad de expresión, ideas políticas, denuncia social, etc.).

\section{Discusión y conclusiones}

El análisis del efecto Ecce Homo lo sintetizamos en cuatro fases conectadas: interacción con emociones, viralización mediática, aceptación como obra artística autónoma y patrimonialización. Asimismo, se desprenden varias líneas de investigación como la influencia de los medios de comunicación en los criterios de restauración, la viralización como vehículo de patrimonialización y el impacto económico como pretexto en la valoración cultural.

De los datos estadísticos recabados se desprende una polarización en el espectador, de manera que se forman facciones entre los que comprenden el alcance y una trascendencia adquirida y los que lo observan como un hecho grotesco.

Del análisis de los comentarios justificando la necesidad de conservar el EHB (ver Fig. 2), podemos concluir que:

a) El espectador percibe a la autora del repinte del EHB con ternura y la narración de los hechos se califica como bienintencionada.

b) Se refuerza la idea de subjetividad en el arte, con referencias a Louis Camnitzer, Francis Bacon o Duchamp, entre otros.

c) El EHB se considera como icono del postmodernismo y del arte alternativo. Se entiende como una iconografía moderna acorde con la contemporaneidad.

d) Existe una aceptación del arte como generador de emociones. El EHB ha producido múltiples reacciones emotivas, la mayoría de ellas relacionadas con la risa o la felicidad.

e) Algunos de los comentarios destacan los valores religiosos que representa, como la bondad y misericordia.

f) La disposición de los hechos ha producido una atracción, filiación y generación de discursos que difícilmente puede competir con el estatismo y localismo de la obra de Elías García. Esto supone una graduación por comparación. Así, se entiende que el EHB consigue un mayor logro en la historia del arte. El impacto mediático lo carga de simbología, de manera que se percibe con mayor valor.

g) Un importante porcentaje tiene una visión mercantil y lo establece como un recurso turístico y comercial.

h) Se entiende que existe una ruptura de la jerarquía vertical autor-espectador, se aplaude la paganización de iconos religiosos y se interpreta como una crítica involuntaria por el hastío de los cánones tradicionales (espíritu subversivo).

i) El argumento reduccionista de "porque sí", lejos de parecer una opinión superflua, nos indica una exaltación de la individualidad.

Destacamos una evolución en la percepción de los hechos transcurridos en Borja a medida que se desarrolla el impacto en los medios de comunicación. En la tabla 1 podemos comprobar cómo los titulares de prensa viran desde las represalias hasta el anuncio de eventos $\mathrm{y}$ actividades culturales en torno o inspirados en el EHB. De estos titulares también se infiere un proceso de metonimia donde el EHB pasa a representar una actividad de restauración con connotaciones negativas. Esto demuestra la relevancia e interiorización de este hecho. Pero, ¿cuáles son los aspectos que contribuyen al impacto mediático y a la eficacia como discurso del EHB?

Entendemos que los sentimientos y emociones derivan en un proceso de patrimonialización posmoderno, donde el EHB surge como renovación de icono anti establishment cultural. Esta eficacia queda engrasada con un proceso de viralización, en el que el hecho de compartir este contenido configura una conciencia de pertenencia al grupo/comunidad, retroalimentando la valorización del EHB como un elemento identitario de dicha comunidad. En definitiva, se produce un desplazamiento del centro de poder: la fabricación continua de nuevos ídolos nihilistas en el que proyectar nuestras propias necesidades de pertenencia al grupo o reflejar el estatus deseado.

Otro de los hechos digno de mención es la elevación a categoría de obra de arte. Se produce un paralelismo con los procesos creativos artísticos actuales, no con intencionalidad, sino como argumento a posteriori derivado del cumplimiento eficaz de la función contemporánea del arte: una gran aptitud hacia la espectacularización y capacidad de compraventa. 
Bergua, Serrano, Valero y Plumed (2013) establecen un matiz en el fenómeno del EHB, diferenciándolo de un concepto de arte dialógico ${ }^{49}$ hacia una concepción de arte dialogado: se acepta la falta de intencionalidad artística del repinte. Sin embargo, su entidad se justifica gracias a las múltiples reflexiones en torno a la idea de arte que origina, debido a la desmonopolización del conocimiento experto ${ }^{50}$. El ámbito del arte tiene un componente elitista, incluso en el proceso de patrimonialización de los objetos histórico-artísticos existe una variable donde los agentes sociales pueden determinar qué elementos son susceptibles de ser o no patrimonio. Es decir, existen personas o entidades que deciden qué es arte y qué no lo es. Sin embargo, la sociedad actual tiende a reaccionar contra el poder establecido. Uno de los conceptos extendidos para justificar determinados argumentos es el enunciado de Beck, Lash, y Giddens: "es preciso abandonar la idea de que las administraciones y los expertos saben exactamente, o al menos mejor, qué está bien y qué está mal para todos; la desmonopolización del conocimiento experto" ${ }^{51}$. Asimismo, "el patrimonio no se define ya única y principalmente desde arriba, ni exclusivamente desde los expertos, sino mediante cooperación y negociación entre una pluralidad de actores" 52 .

De esta forma, la persona lega en la materia reivindica su papel preponderante en la gestión del conocimiento, en una idea mal entendida de democratización del mismo. En el caso del EHB, se fue aceptando como obra de arte autónoma. A pesar de que su autora no tuvo esa intencionalidad, el carácter dialógico y la desmonopolización del conocimiento experto (y la rebelión contra poderes establecidos), lo alzaron a la categoría de obra de arte. Del mismo modo, el EHB encarna el elogio hacia la visión particularista del individuo frente a la muerte del metarrelato histórico. Por lo tanto, identificamos una aversión hacia la imposición

\footnotetext{
49 BAKHTIN, Mikail, Art and answerability, University of Texas Press, Austin, 1990 y KESTER, Grant, Conversation pieces: community and communication in modern art, University of California Press, Los Ángeles, 2004.

50 BERGUA, José Ángel; SERRANO, C.; VALERO, Diana y PLUMED, Marta, "Sociedad red..., opus cit., p. 496.

51 BECK, Ulrich, LASH, Scott y GIDDENS, Anthony, Modernización reflexiva: politica, tradición y estética en el orden social moderno, Alianza Editorial, Madrid, 1997, p.46.

52 ARIÑO VILLARROYA, Antonio, "La patrimonialización de...", opus cit., p. 138.
}

de patrones estéticos, o la prescripción de qué elementos deben restaurarse.

No obstante, en nuestro juicio, esta desmonopolización carece de universalidad (piénsese en situaciones extremas en Medicina o en Derecho). En última instancia se produce un recambio de predicamento entre el conocimiento experto y el profano, que no garantiza la veracidad de los argumentos. A pesar de lo dicho, existe una relatividad en el valor de una obra de arte que va a depender de la edad, la formación o nivel sociocultural de las personas, y ahora, de la repercusión mediática y sus cauces virtuales. En este sentido, uno de los aspectos relevantes lo encontramos en el aura que desprende toda obra expuesta en un contexto preciso. Este hecho nos recuerda a la obra de Marcel Duchamp- que juega con estos mecanismos, descontextualizando objetos seriados y reubicándolo en espacios culturales. Éstos ayudan a la sacralización de las obras. Las nuevas tecnologías y los nuevos espacios virtuales también pueden actuar como elementos sacralizadores, de forma que la mera presencia masiva en medios de comunicación establezca el grado de veracidad. Así, en el caso del EHB se produce una apropiación simbólica como obra de arte y objeto patrimonial coadyuvado por su contexto de fenómeno viral.

Otra de las repercusiones es la influencia social en los criterios de restauración. Conscientes de la complejidad entre la teoría y la práctica, para Muñoz Viñas, se restaura la "capacidad para funcionar como símbolo, y esta capacidad depende esencialmente de sus rasgos perceptibles" ${ }^{53}$. No cabe duda de que el repinte del EHB cumple de forma mucho más eficaz una función contemporánea. Con lo cual prevalece este nuevo estado de autenticidad sobre el original, considerándolo más valioso, de más interés (ver Fig. 2). Así, se cuestiona el concepto de objetividad que queda reemplazado por el "gusto", es decir, con la concepción subjetiva idealizada del aspecto.

La autenticidad, la originalidad y la calidad son conceptos fundamentales para la valoración de una obra ${ }^{54}$. Morón de Castro destaca que estos conceptos descansan sobre un juicio

\footnotetext{
MUÑOZ VIÑAS, Salvador, Teoría contemporánea de la Restauración, Ed. Síntesis, Valencia, 2003, p. 80.

54 MORÓN DE CASTRO, María Fernanda, "Valoración y tasación de obras de arte", en Mus-A: Revista de los museos de Andalucía, № 2, Sevilla, 2003, pp. 68-69.
} 


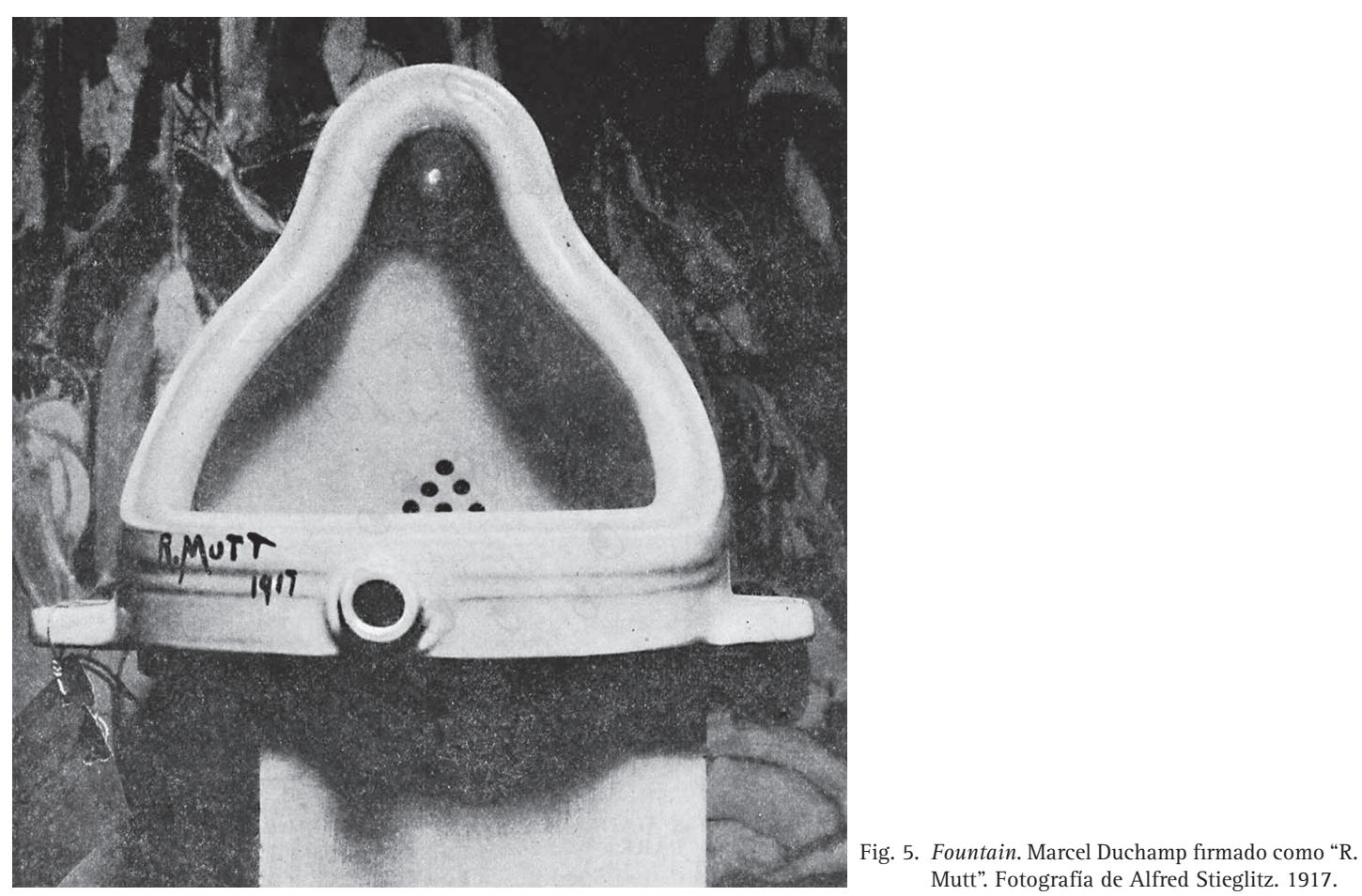

de valor. Es decir, un especialista, desde su experiencia y conocimiento, valora en el plano mental, plástico y técnico, si una determinada pieza alcanza un nivel de excelencia, o lo que es lo mismo, es adecuada a sus fines ${ }^{55}$.

En el panorama artístico actual, la calidad se puede alcanzar pasando por otro tipo de fines como el carácter de generar reflexión, sorpresa, denuncia sociopolítica, o, por el contrario, tener una condición nihilista. También existe una deriva del arte contemporáneo hacia el espectáculo ${ }^{56}$. Es decir, la definición de un objeto artístico o patrimonial pasa por establecer su dinámica de relaciones con su contexto.

De esta forma, la autenticidad del EHB no se sustenta sobre principios fijos, histórico-artísticos o científicos, sino sobre cuestiones variables como el uso o la función por la eficacia de sus valores simbólicos (identitarios, sentimentales, económicos), un consumo de novedad (producto del impacto viral) y una preminencia de las emociones. La galería actual demanda una obra que cumpla con las sacrosantas funciones contemporáneas, a saber, capacidad de compraventa, novedad y exaltación del individualismo frente a poderes establecidos.

\footnotetext{
55 Idem.

56 MORÓN DE CASTRO, María Fernanda, "Valoración y tasación...", opus cit., p. 69.
}

Por otro lado, un pensamiento popular sobre la restauración de bienes culturales admite los postulados renacentistas donde la vertiente artística y creadora se impone a la conservación de los objetos del pasado (para disponer de la superficie que ocupa el fresco del Juicio Final, Miguel Ángel tuvo que eliminar varias decoraciones pictóricas existentes). Es decir, no importa destruir trabajos previos, si se entiende que el reemplazo es por una obra mejor.

Como se ha visto, uno de los argumentos recurrentes a favor del EHB consiste en la superación del original (ver Fig.2) y la poca relevancia del mismo (ver Fig. 1). Otro factor indicativo de la valorización del repinte es que la nueva pintura tiene una serie de estrategias de conservación preventiva que no disfrutaba la imagen subyacente, como por ejemplo, una lámina transparente que lo protege.

Sin embargo, el informe técnico de restauración plantea la eliminación del repinte de 2012 aduciendo al respeto al original (pintura religiosa para un lugar de culto) y siendo consciente de la "ola mediática". Destaca el rechazo del repinte como obra original puesto que la autora sólo pretendía reparar unos daños. No obstante, también se plantean como alternativa 
el arranque y separación de las pinturas para conservar ambas ${ }^{57}$.

Este hecho pone de manifiesto la dificultad de mantener los criterios de intervención ante la presión social y mediática, como ocurre también en las populares esculturas policromadas que adquieren una tez morena por las acumulaciones superficiales. Es decir, una propuesta de tratamiento clara se ve coartada por un contexto de viralidad, donde el EHB pasa a vincularse con una identidad cultural posmoderna. Porque, en estos casos, la intervención de restauración dejaría de actuar sólo en la materialidad de la obra y produciría una alteración en la significación del bien.

En el argumento de la imposición del repinte como criterio de "no intervención" del EHB, tiene mucho que ver su instrumentalización economicista. Además, la temprana aceptación como potencial recurso dinamizador (ver figs. 1,2 y 4) demuestra el reduccionismo que sufre el patrimonio cobijado en determinado turismo cultural. Éste puede concebirlo como un camino rápido, provechoso y rentable (el EHB no ha requerido ni necesita la inversión institucional) en un mercado turísticos en el que el patrimonio es visto como un recurso que ha de adaptarse a la demanda ${ }^{58}$. Los objetos culturales son muy sensibles a los fenómenos de fetichización. Así, estos elementos se convierten en un objetivo sugerente de aprovechamiento económico por su condición de extraordinario, único, exclusivo, etc., que lo hacen muy atractivo para el turismo, en lo que se conoce como renta simbólica ${ }^{59}$.

El profesor Muñoz Viñas, defiende el diálogo entre las partes implicadas, reconociendo la responsabilidad de los agentes cualificados, pero teniendo en cuenta a los usuarios. De esta manera, "la ética contemporánea de la restauración pretende contemplar el mayor número posible de formas de entender el objeto y atender equilibradamente a todas sus funciones: no sólo a las que cumple para los expertos, sino también a las que cumple para el resto de los usuarios" $"$.
57 RIPOLLÉS ADELANTADO, Ma Encarnación y NÚÑEZ MOTILVA, Ma Mercedes, Informe sobre el Ecce Homo..., opus cit.
58 AGUDO TORRICO, Juan, "Patrimonio etnológico...”, opus cit., p. 197.

59 MACHUCA, Jesús Antonio, "Percepciones de la cultura en la posmodernidad", en Alteridades, № 16, México, 1998, p. 36.

60 MUÑOZ VIÑAS, Salvador, Teoría contemporánea..., opus cit., p. 162. 